\title{
Comparative study of expression of keratins 8, 10, 13 and 17 in CIN III and invasive carcinoma of cervix
}

\author{
Bundela A. ${ }^{1}$, Bundela A. ${ }^{2}$, Vahikar S.U. ${ }^{3}$, Srivastava K. ${ }^{4}$, Goyal A.K. ${ }^{5}$ \\ ${ }^{1}$ Dr. Alpana Bundela, Assistant Professor, ${ }^{2}$ Dr. Archana Bundela, Assistant Professor, ${ }^{3}$ Dr. Shilpa U. Vahikar, Associate \\ Professor, ${ }^{4}$ Dr. Kanchan Srivastava, Associate Professor; all authors are attached with Department of Pathology, B.R.D \\ Medical College Gorakhpur. ${ }^{5}$ Dr. Ashish Kumar Goyal, KGMC, (U.P.) India.
}

Corresponding Author: Dr. Archana Bundela, Assistant Professor, Department of Pathology, B.R.D Medical College Gorakhpur (U.P.) India. E-mail: archanaotober79@gmail.com

\begin{abstract}
Introduction: The role of keratin expression patterns as candidate tumour markers continues to be under investigation in human cervix carcinogenesis. Keratin comprise of family of at least 20 intermediate filament proteins that have a specific distribution pattern in epithelial tissue. Objective: The present study was conducted with an aim to identify CINI, II and CINIII in tissue sections with the help of immunohistochemistry of specific diagnostic markers so as to reduce the burden of invasive cervical carcinoma and to evaluate the role of cytokeratin 8,10,13 and 17 for differentiating CINIII from cervical carcinoma along with its correlation with histopathological diagnosis of these lesions. Method: We examined the immunohistochemical staining of CK8, CK10, CK13 and CK17 in 64 cases of reference cervix, CINIII lesions and invasive cervical carcinoma. Results: In present study cytokeratin 8 has sensitivity $40 \%$ and specificity $100 \%$, cytokeratin 10 has sensitivity $80 \%$ and specificity $40 \%$, cytokeratin 13 has sensitivity $100 \%$ and specificity $80 \%$ and cytokeratin 17 has sensitivity $40 \%$ and specificity $100 \%$ in invasive cervical carcinoma. In the CIN III lesions, cytokeratin 8 has sensitivity $56 \%$ and specificity $100 \%$, cytokeratin 10 has sensitivity $80 \%$ and specificity $79 \%$, cytokeratin 13 has sensitivity $100 \%$ and specificity $75 \%$ and cytokeratin 17 has sensitivity $72 \%$ and specificity $100 \%$ in cervical intraepithelial lesion III. Conclusions: We observed that expression of keratins 8 and 17 and loss of keratins 10 and 13 are good markers of malignant transformation in human cervix. Keratin expression patterns, namely expressions of keratin 10 can be useful for studying and grading squamous cell carcinomas of the cervix.
\end{abstract}

Key words: Invasive cervical carcinoma, Keratins, Immunohistochemistry, Immunohistochemical staining

\section{Introduction}

Worldwide, cervical cancer is both the fourth most common cause of cancer and the fourth most common cause of death from cancer in women [1]. Approximately $70 \%$ of cervical cancers occur in developing countries [2]. It is the one of leading cause of cancer mortality, accounting for $17 \%$ of all cancer deaths among women aged between 30 and 69 years. It is estimated that cervical cancer will occur in approximately 1 in 53 indian women during their lifetime compared with 1 in 100 women in more developed regions of world. [3]. Among women, it is the leading cause of cancer mortality, accounting for $26 \%$ of all cancer deaths [4]. CIN is not cancer, most cases of CIN remain stable, however a small percentage of cases progress to become cervical cancer, usually cervical squamous cell carcinoma. (SCC) if left

Manuscript received: $20^{\text {th }}$ April 2019

Reviewed: $30^{\text {th }}$ April 2019

Author Corrected: $7^{\text {th }}$ May 2019

Accepted for Publication: 14 $4^{\text {th }}$ May 2019 untreated [5]. In histologic diagnosis of CIN which might be improved by more specific diagnostic biomarker. Keratin comprise of family of at least 20 intermediated filament proteins that have a specific distribution in epithelial tissue [6]. Several studies have shown that changes in the pattern of keratin expression occur during neoplastic transformation in the uterine cervix. Keratin phenotypes may be useful in differential diagnostic considerations when distinguishing between keratinizing and nonkeratinizing (using keratin 10, 13 and 16 antibodies) carcinomas and poorly differentiated adenocarcinomas.

Keratin 17 may also be useful in distinguishing carcinomas of cervix from those of colon and also from mesotheliomas. Furthermore, the presence of keratin 17 in CIN I, II or III lesion may indicate progressive potential while its absence could be indicative of a regressive behaviour. Because most carcinomas express 
keratins 8,14,17,18 and 19 [7] and our Particular interest are the changes of keratin $8,10,13,17$ that occur from reference cervix to pre invasive and invasive carcinoma. P Maddox et al (1994) [8] examined the value of immunohistochemistry by differential expression of keratins 10,17 and 19 in normal cervical epithelium, cervical intraepithelial neoplasia and cervical carcinoma.

The Present study was conducted with an aim to identify CIN I, II and III in tissue sections with the help of immunostaining of specific diagnostic markers so as to reduce the burden of invasive cervical carcinoma and, and to evaluate the role of cytokeratin $8,10,13$ and 17 for differentiating CIN III from cervical carcinoma along with its correlation with histopathological diagnosis of these lesions.

\section{Material and Methods}

The present retrospective study has been conducted in the Department of Pathology, B.R.D. Medical College, Gorakhpur, on the patients attending the OPD and on admitted patients in wards of Gynaecology Department, Nehru Chikitsalaya, Gorakhpur during a period ranging from August 2011 to September 2012. Freshly biopsied specimens were preserved for preparing paraffin blocks by routine method in the histopathology laboratory and retrospective study has also been performed on preserved blocks of $1.5 \times 2.0 \times 1.5 \times 1.5 \mathrm{~cm}$ size. We studied the sample obtained from hysterectomy specimen and cervical biopsies.

All the paraffin blocks are prepared were preserved for section cutting. Thin sections of $4-5 \mu$ have been, cut after dewaxing then were stained by hematoxylinand eosin stain. Histopathological diagnosis was made and then freshly cut sections were also used for immunostaining.

\section{Results}

Following observations were made during the study-

\section{Original Research Article}

Out of 64 cases, 10 cases were of CIN III lesion and 44 cases were of invasive cervical carcinoma, 10 cases are also observed of reference cervix for comparative evaluation and on the basis of histological diagnosis in invasive cervical carcinoma, 19 cases were diagnosed as well differentiated squamous cell carcinoma (keratinizing squamous cell carcinoma).

23 cases were diagnosed as moderately differentiated squamous cell carcinoma (large cell non keratininzing squamous cell carcinoma) and 2 cases were diagnosed as poorly differentiated (small cell non keratinizing squamous cell carcinoma.

Immunostaining- Four-micron tissue sections were cut from selected blocks and positioned on poly-L-lysine coated slides. After deparaffinization and rehydration, antigen retrieval was performed using citrate buffer (pH 6.0) at $121^{\circ} \mathrm{C}$ for $10 \mathrm{~min}$.

Endogenous peroxidase activity was blocked by $3 \%$ hydrogen peroxide for $5 \mathrm{~min}$. The primary antibodies used in this study were CK8, CK10, CK13 and CK17.

Scoring- All cases with stained cells were considered positive. A semiquantitative approach was used to score the staining,$+<5 \%$ of immunoreactive cells ++ , between $5 \%$ and $50 \%$ of immunoreactive cells, +++, between $50 \%$ and $75 \%$ of immunoreactive cells and ,$++++>75 \%$ of immunoreactive cells.

Statistical Analysis- Statistical analysis was performed by using percentage, mean and median. Two values were considered significantly different at $\mathrm{P}<0.05$ and were considered suggestively different at $\mathrm{P}<0.10$ Because of technical limitations, some samples could not be analysed.

Out of 64 cases, 10 cases (15.62\%) were of CIN III lesion and 44 cases $(68.75 \%)$ cases were of invasive cervical carcinoma, 10 cases $(15.62 \%)$ are also observed of reference cervix for comparative evaluation and on the basis of histological diagnosis in invasive cervical carcinoma,19 cases $(43.18 \%)$ were diagnosed as well differentiated squamous cell carcinoma (keratinizing squamous cell carcinoma). 23 cases $(52.27 \%)$ were diagnosed as moderately differentiated squamous cell carcinoma (large cell non keratininzing squamous cell carcinoma) and 2 cases were diagnosed as poorly differentiated (small cell non keratinizing squamous cell carcinoma. The most common age group for CINIII to occur was found to be fourth decade (40\%) followed by fifth decade (30\%) and then by third, sixth and seventh. Mean age of CIN III lesion is 42 and standard deviation of age is 11 for this distribution. The most common age group for invasive squamous cell carcinoma to occur was found to be fifth decade 13 cases $(29.54 \%)$ followed by sixth decade, 9 cases $(20.45 \%)$ and then by forth, seventh, third decade and eighth decade. Mean age for cervical carcinoma is 48.41 years. $\mathrm{Z}$ score for age distribution is 1.552025 and $\mathrm{p}$ value is more than 0.05 which is not significant in age distribution. Table- 1 is showing distribution and comparative evaluation of percentage of cases showing positivity for cytokeratin $8,10,13$ and 17 marker. 


\section{Original Research Article}

Table-1: Comparative evaluation of cytokeratin 8, 10, 13 and 17 in reference cervix, CIN III lesion and invasive cervical carcinoma.

\begin{tabular}{|c|c|c|c|c|c|c|}
\hline Cytokeratin & $\begin{array}{c}\text { No. of cases } \\
\text { of Normal } \\
\text { cervix }\end{array}$ & Percentage & $\begin{array}{c}\text { No. of cases } \\
\text { in CIN III } \\
\text { lesions }\end{array}$ & Percentage & $\begin{array}{c}\text { No. of cases in } \\
\text { invasive cervical } \\
\text { carcinoma }\end{array}$ & percentage \\
\hline CK $8+v e$ & 0 & $0 \%$ & 4 & $40 \%$ & 25 & $56.8 \%$ \\
\hline CK10+ve & 8 & $80 \%$ & 6 & $60 \%$ & 9 & $20.45 \%$ \\
\hline CK13+ve & 10 & $100 \%$ & 2 & $20 \%$ & 11 & $25 \%$ \\
\hline CK17+ve & 0 & $0 \%$ & 4 & $40 \%$ & 32 & $72.72 \%$ \\
\hline $\begin{array}{c}\text { Total no. of } \\
\text { cases }\end{array}$ & $\mathbf{1 0}$ & $\mathbf{1 0 0 \%}$ & $\mathbf{1 0}$ & $\mathbf{1 0 0 \%}$ & $\mathbf{4 4}$ & $\mathbf{1 0 0 \%}$ \\
\hline
\end{tabular}

For cytokeratin $8, \mathrm{P}$ value is less than 0.01 and less than 0.001 respectively when reference cervix compared with CIN III and invasive cervical carcinoma, but $\mathrm{P}$ value is not significant in CIN III versus invasive cervical carcinoma. The difference in keratin 10 expression among the 3 groups of lesions is statistically significant. It was significantly lower in invasive carcinoma than in reference cervix. Statistically $\mathrm{P}$ value is less than 0.001 when compared between normal cervix and invasive cervical carcinoma. For cytokeratin 13, statistically $\mathrm{P}$ value is less than 0.001 in normal cervix versus CIN III and less than 0.001 in normal cervix versus invasive cervical carcinoma. But statistically $\mathrm{P}$ value is not significant in CIN III versus invasive cervical carcinoma. For cytokeratin 17 statistically $\mathrm{P}$ value is less than 0.01 in normal cervix versus CIN III and P value is less than 0.001 in normal cervix versus invasive cervical carcinoma. Statistically $\mathrm{P}$ value is less than 0.05 in CIN III versus invasive carcinoma which is significant.

Table-2 is showing comparison between expression of keratins in keratinizing and non keratinizing squamous cell carcinoma and on statistical analysis we found the P values 0.06 for keratin 8,0.004 for keratin 10,.0.06 for keratin 13 and 0.08 for keratin 17 .

Table-2: Comparison between expression of keratins and histopathologic classification of squamous invasive carcinoma.

\begin{tabular}{|c|c|c|c|c|c|}
\hline Cytokeratin & \multicolumn{2}{|c|}{$\begin{array}{c}\text { Keratinizing squamous cell } \\
\text { carcinoma }\end{array}$} & \multicolumn{2}{c|}{$\begin{array}{c}\text { Non keratinizing squamous } \\
\text { cell carcinoma }\end{array}$} & P value \\
\hline Keratin $8+\mathrm{ve}$ & 7 & $36.84 \%$ & 18 & $72 \%$ & $\mathbf{0 . 0 6}$ \\
\hline keratin $10+\mathrm{ve}$ & 8 & $42.10 \%$ & 0 & $0 \%$ & $\mathbf{0 . 0 0 4}$ \\
\hline Keratin 13+ve & 8 & $42.10 \%$ & 4 & $16 \%$ & $\mathbf{0 . 0 6}$ \\
\hline Keratin 17+ve & 16 & $84.21 \%$ & 15 & $60 \%$ & $\mathbf{0 . 0 8}$ \\
\hline Total no. of cases & 19 & $100 \%$ & 25 & $100 \%$ & \\
\hline
\end{tabular}

Table-3: Table showing number of positive and negative cases in CIN III lesion and invasive cell carcinoma.

\begin{tabular}{|c|c|c|c|c|c|c|c|c|}
\hline & \multicolumn{2}{|c|}{$\begin{array}{c}\text { No. of cases of } \\
\text { cytokeratin } \mathbf{8} \text { in } \\
\text { CINIII and } \\
\text { invasive cervical } \\
\text { carcinoma }\end{array}$} & $\begin{array}{c}\text { No. of cases of } \\
\text { cytokeratin 10 in } \\
\text { CINIII and } \\
\text { invasive } \\
\text { cervical carcinoma }\end{array}$ & $\begin{array}{c}\text { No. of cases of } \\
\text { cytokeratin } 13 \text { in } \\
\text { CINIII and } \\
\text { invasive } \\
\text { cervical carcinoma }\end{array}$ & $\begin{array}{c}\text { No. of cases of } \\
\text { cytokeratin 17 in } \\
\text { CINIII and } \\
\text { invasive } \\
\text { cervical carcinoma }\end{array}$ \\
\hline True positive cases & 4 & 25 & 8 & 8 & 10 & 10 & 4 & 32 \\
\hline False positive cases & 0 & 0 & 6 & 9 & 2 & 11 & 0 & 0 \\
\hline True negative cases & 10 & 19 & 4 & 35 & 8 & 33 & 10 & 10 \\
\hline False negative cases & 6 & 19 & 2 & 2 & 0 & 0 & 6 & 12 \\
\hline Total & $\mathbf{2 0}$ & $\mathbf{5 4}$ & $\mathbf{2 0}$ & $\mathbf{5 4}$ & $\mathbf{2 0}$ & $\mathbf{5 4}$ & $\mathbf{2 0}$ & $\mathbf{5 4}$ \\
\hline
\end{tabular}

Total true positive and true negative cases are summarised in table Table-3. 
Original Research Article

Table-4: Comparison of sensitivity and specificity of cytokeratin 8, 10, 13 and 17 in CIN III and invasive cervical carcinoma.

\begin{tabular}{|c|c|c|c|c|c|c|c|c|}
\hline & \multicolumn{4}{|c}{ Sensitivity } & \multicolumn{4}{c|}{ Specificity } \\
\hline & CK 8 & CK10 & CK13 & CK17 & CK8 & CK10 & CK13 & CK17 \\
\hline CIN III lesions & $40 \%$ & $80 \%$ & $100 \%$ & $40 \%$ & $100 \%$ & $40 \%$ & $80 \%$ & $100 \%$ \\
\hline $\begin{array}{c}\text { Invasive Cervical } \\
\text { carcinoma }\end{array}$ & $56 \%$ & $80 \%$ & $100 \%$ & $72 \%$ & $100 \%$ & $79 \%$ & $75 \%$ & $100 \%$ \\
\hline
\end{tabular}

Table 4 showing, Cytokeratin 8 positivity is observed early in preinvasive malignancy, CIN III with sensitivity $40 \%$ and specificity $100 \%$ and in invasive carcinomas with sensitivity $56 \%$ and specificity $100 \%$. But in reference cervix it is negative in all cases so it can be a useful marker to distinguish reference cervix from CIN III and invasive carcinoma. Cytokeratin 10 has sensitivity $80 \%$ and specificity $40 \%$ in CIN III lesions and in invasive carcinoma is $80 \%$ and specificity is $79 \%$. There is loss of expression when compared with the case of reference cervix. Cytokeratin 13 has sensitivity $100 \%$ and specificity $80 \%$ in CIN III lesions and in invasive carcinoma sensitivity is $100 \%$ and specificity is $75 \%$. There is loss of expression with increasing malignant transformation. It is little more specific for CIN III lesions. Cytokeratin 17 has sensitivity $40 \%$ and specificity 100\% in CIN III lesions and in invasive carcinoma sensitivity is $72 \%$ and specificity is $100 \%$. So it is specific marker of invasive carcinoma and can be useful to distinguishing CIN III and invasive cervical carcinoma.

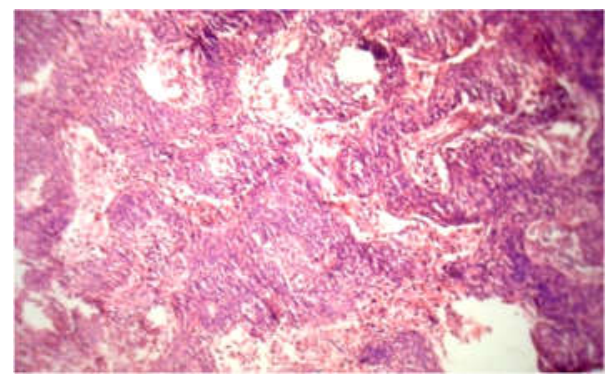

Figure-1: Squamous cell carcinoma of cervix, large cell nonkeratinizing type. Tumor cells have abundant eosinophilic cytoplasm and distinct cell borders to suggest individual cell keratinization. The irregular, large nuclei contain multiple nucleoli. (Hematoxylin-eosin stain, original magnification 400.)

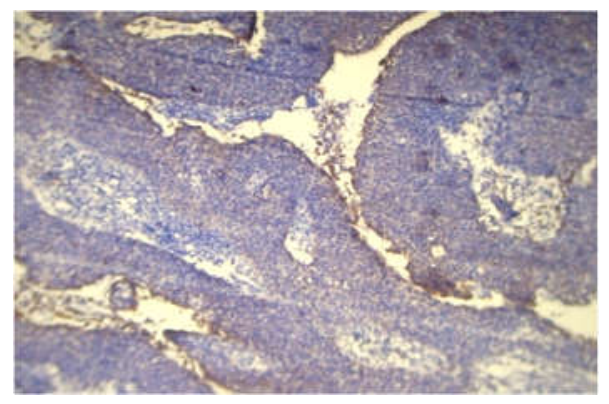

Figure-2: Moderately differentiated squamous cell carcinoma

(large cell non keratinizing carcinoma) showing diffuse cytoplasmic positivity for cytokeratin 8

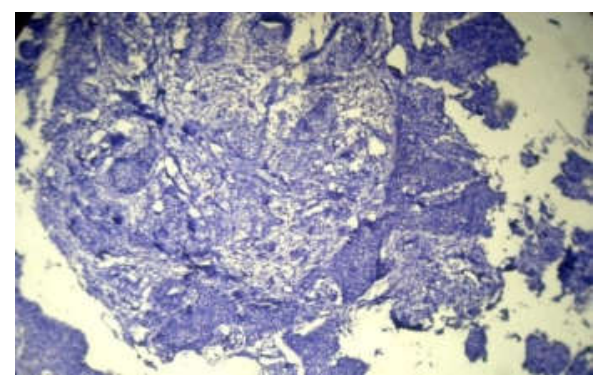

Figure-3: Moderately differentiated squamous cell carcinoma,

(large cell non keratinizing carcinoma) showing negativity for cytokeratin 10 


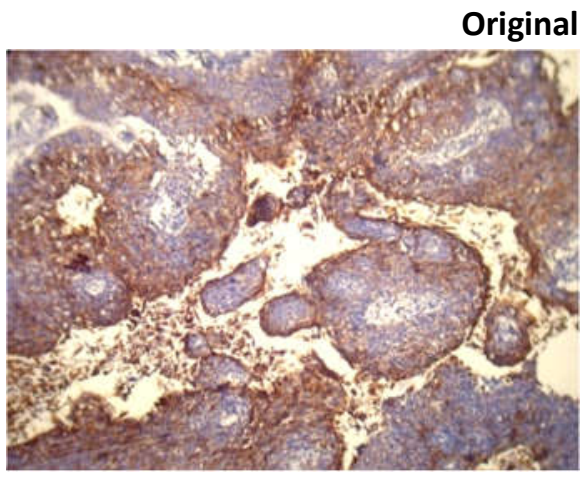

Figure-4: Moderately differentiated squamous cell carcinoma,

(large cell non keratinizing carcinoma) showing diffuse cytoplasmic positivity for cytokeratin 13

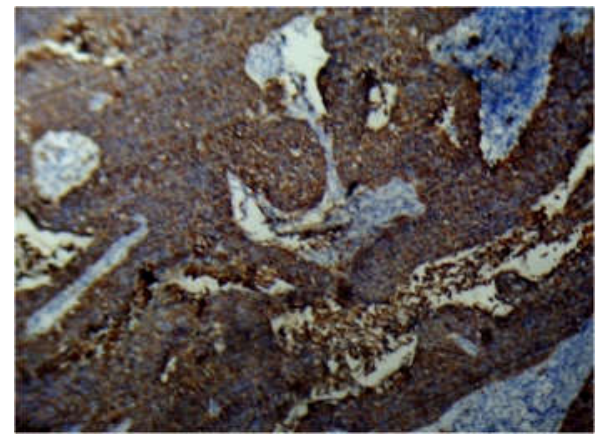

Figure-5: Moderately differentiated squamous cell carcinoma

(large cell non keratinizing carcinoma) showing diffuse cytoplasmic positivity for cytokeratin 17

\section{Discussion}

In context to the cases selected for study, the age of patients presenting with CIN III ranged from second decade to eight decade with a mean age of 42 years. Maximum cases were seen in the 4rth decade followed by 5th decade and then by third, sixth and seventh decade. No cases found in eighth decade and second decade. Results of previous studies are that Nartam Sharma et al [9], studied 361 cases of CIN III and showed that the incidence of CIN III was maximum in the age group of 30-50 years. N Ahmad et al [10] reported that out of 7 cases of CIN III lesions, maximum cases were found in the fourth decade.

Torrisi A et al [11], reported that the incidence of CIN III has been evaluated in 520 patients. $48.92+/-13.89$ years is the mean age of incidence. Severe dysplasia reaches its maximum incidence in the fourth decade. Carcinoma in situ has the highest mean age, reaching its maximum incidence in the fifth decade. Herbart A et al [12] studied that $90 \%$ of patients of CIN III are diagnosed under 50 years, who done a 3-year study of the population of Southampton and south-west Hampshire, there were 10 times as many cases of CIN III compared with invasive squamous carcinoma (700 compared with 70). In the present study, most of the patients of CIN III were from the age group of 30-50 years which is in accordance with, Nortam Sharma et al,
2012, N Ahmed et al, Torrisi et al, and Herbart A et al, indicating the commonest age group of CIN III lesions is fourth decade of life. Analysing the results of other workers was noticed that Jha et al, [13] analysed 3370 cases of invasive carcinoma cervix. Majority of the patients were in the age group of 40-50 years. Schiffman MH et al [14]-identified 500 cases of carcinoma cervix and showed that the incidence of carcinoma cervix was maximum in the age group of 3050 years. Park TWet al, [15] reported that median age for invasive cervical carcinoma in the UK is 35 to 45 years. Zoe R. et al [16] reported that median age of cervical carcinoma is 48 years.

The majority of women with invasive squamous cell carcinoma of the cervix (SCC) are diagnosed in their mid-40s or 50s, although some women are diagnosed much earlier. In our study is in accordance with Jha et al, How Schiffman MH et al, Park TW et al and Zoe R.et al, indicating the commonest age group of carcinoma cervix is the between 4th to 5th decade of life. In the present study, maximum number of cases were in the para 5-6 which is accordance with the studies done by Parveen et al, 2017 [17], Satya B. Paul [18]. Above findings indicate that nulliparity is one of the important risk factor for development of carcinoma cervix. 
According to present study commonest morphological type is moderately differentiated squamous cell carcinoma (large cell non keratinizing squamous cell carcinoma). Majority of cases $(52.27 \%)$ are found of moderately differentiated squamous cell carcinoma. Similar findings were noticed by other workers as follows-Goellner J.R.et al [19] observed that majority of cases $61.02 \%$ were of large cell non keratinizing squamous cell carcinoma. Verma K and Kapila K [20] found $74 \%$ of carcinoma cervix were of squamous cell carcinoma, large cell non keratinizing type. Mitra Subir et al [21] observed that majority of cases that is $83.95 \%$ were of squamous cell carcinoma.

In the present study we observed that expression of cytokeratin 8,10,13 and 17 was different in CIN III and invasive cervical squamous cell carcinoma. Expression of cytokeratins 8 and 17 increased from reference cervix to invasive carcinomas, in contrast expression of cytokeratin 13 was lost with increasing severity of lesions.

Lower expression of keratin 10 is observed in invasive carcinoma when compared with the case of reference cervix. Expression of cytokeratin 8 and 17 was more frequent with increasing severity of lesion.

Carla carrilho et al [22] in their study showed that out of total 42 cases of invasive cervical carcinoma, 57.1\% cases showed positivity for cytokeratin $8,73.2 \%$ cases were positive for cytokeratin 10 and $25 \%$ cases were positive for cytokeratin 13. Ikeda et al [23] in their study found that out of total 43 cases of invasive cervical carcinoma, $71.4 \%$ cases were positive for cytokeratin 8 and $95.2 \%$ cases were positive for cytokeratin 10 .

Smarouladivani et al [24] in their study observed that out of 21 total cases of invasive cervical carcinoma $86.9 \%$ cases showed positivity for cytokeratin 8 and $100 \%$ cases were positive for cytokertin 10 .

The results of immunohistochemical markers of cytokeratin 8, 17 and 13 in invasive cervical carcinoma of the present study are in concurrence with the observation of Carla carrilho et al [22], 2004, Ikeda et al [23], 2008, Smarouladivani et al [24], 2010, that shows the expression of cytokeratin 8 and 17 with loss of expression of cytokeratin 13 in invasive carcinomas.

In the present study cytokeratin 10 was positive in $80 \%$ cases of reference cervix, $77 \%$ cases of invasive cervical carcinoma. Cytokeratin 17 was positive in $0 \%$ cases of reference cervix and was positive in $80 \%$ cases of invasive cervical carcinoma.

\section{Original Research Article}

Maddox et al [8], 1994, in their study found that in reference cervix $40 \%$ cases were positive for cytokeratin 10 and only $1 \%$ cases were positive in invasive cervical carcinoma. Cytokeratin 17 was negative in all cases and $80 \%$ cases were positive in invasive cervical carcinoma.

In present study cytokeratin 8 has sensitivity $40 \%$ and specificity $100 \%$, cytokeratin 10 has sensitivity $80 \%$ and specificity $40 \%$, cytokeratin 13 has sensitivity $100 \%$ and specificity $80 \%$ and cytokeratin 17 has sensitivity $40 \%$ and specificity $100 \%$ in invasive cervical carcinoma. carlacarrilho et. Al [22]. 2004, in their study they found sensitivity of cytokeratin 8 is $44.4 \%$ and specificity $100 \%$, sensitivity of cytokeratin 10 is $77.8 \%$ and specificity $60 \%$. sensitivity of cytokeratin 13 is $100 \%$ and specificity is $77.8 \%$ and sensitivity of cytokeratin 17 is $40 \%$ and specificity $100 \%$.

The results of present study are in accordance with the observations done by Carla carrilho.et al [22], 2004 indicating cytokeratin 8 and 17 are more specific and 10 and 13 are more sensitive for invasive cervical carcinomas.

In the CIN III lesions present study showed the following results, cytokeratin 8 has sensitivity $56 \%$ and specificity $100 \%$, cytokeratin 10 has sensitivity $80 \%$ and specificity $79 \%$, cytokeratin 13 has sensitivity $100 \%$ and specificity $75 \%$ and cytokeratin 17 has sensitivity $72 \%$ and specificity $100 \%$ in cervical intraepithelial lesion III. Carla carrilho et al [22], 2004 found sensitivity of cytokeratin 8 is $57.1 \%$ and specificity $100 \%$.

Sensitivity of cytokeratin is $81 \%$ and specificity $77.8 \%$, sensitivity of cytokeratin 13 is $100 \%$ and $75 \%$ and sensitivity of cytokeratin 17 is $73.2 \%$ and specificity $100 \%$. The results of present study are in accordance with the study done by Carla carrihlo et al [22], 2004.

\section{Conclusion}

In the present study, we concluded that expression of keratins 8, 10, 13 and 17 was different in neoplastic lesions when compared with the case of reference cervix. Expression of keratins 8 and 17 increased, was significantly more frequent in CIN III lesions and invasive carcinoma than in reference cervix, where it was never detected. Our results suggest that keratin 8 was a specific marker for malignant transformation at a pre-invasive stage (CIN III lesions) and in invasive carcinoma, despite a relatively low sensitivity. The same trend was observed for keratin 17. Positivity for 
keratin 17 is a specific marker of invasive carcinoma and can be useful to distinguish CIN III lesions from invasive carcinomas. Expression of keratins 10 and 13 was significantly lower in invasive carcinoma than in reference cervix. In conclusion our results show an altered expression of keratin 8, 17, 10 and 13 during the process of carcinogenesis. Expression of keratins 8 and 17 and loss of keratins 10 and 13 are good markers of malignant transformation.

What this study adds to existing knowledge- The current system for classifying cervix squamous carcinoma into keratinizing and nonkeratinizing subtypes is based on the presence or absence of keratin pearls.

Similarly the histological grading systems are largely dependent upon the degree of keratinisation of the tumors. Our data suggest that more accurate subtyping and grading system could be achieved by use of keratin markers of define well differentiated keratinizing carcinoma. Expression of keratins 8 and 17 and loss of keratins 10 and 17 are good markers of malignant transformation. Keratin expression patterns, namely expression of keratin 10 can be useful for subtyping and grading squamous cell carcinoma of cervix.

Acknowledgement- We wish to thank our co-authors and pathologist Dr Archana, Dr Shilpa, and Dr Ashish Goyal and all the members of department of pathology and gynecology for their valuable contribution in present study.

Abbreviations- CIN, Cervical intraepithelial neoplasia.

Findings: Nil; Conflict of Interest: None initiated Permission from IRB: Yes

\section{References}

1. McGuire S. World Cancer Report 2014. Geneva, Switzerland: World Health Organization, International Agency for Research on Cancer, WHO Press, 2015. Adv Nutr. 2016 Mar 15;7(2):418-9. doi: 10.3945/an. 116. 012211. Print 2016 Mar.

2. Kent A. HPV Vaccination and Testing. Rev Obstet Gynecol. 2010 Winter;3(1):33-4.

3. Morrison AS.Screening in chronic disease.2nd ed. Newyork: Oxford University Press; 1992. Introduction; pp 3-42.

4. GIOBOCON 2002, IARC 2009" database: summary table by cancer". Archived from the original on 200806-16. Retrieved 2008-10-26.

\section{Original Research Article}

5. FDA Licenses New Vaccine for Prevention of Cervical Cancer". U.S. Food and Drug Administration. 2006-06-08.

6. W. Frank, E Schmid, K. Weber and M. Osborn. (June1979). Intermediate -sized filaments of human endothelial cells" The journal of cell biology 1979 june; 81(3):570-80.doi: 10.1083/jcb.81.3.570

7. Smedts F, Ramaekers F, Troyanovsky S, et al. Keratin expression in cervical cancer. Am J Pathol. 1992 Aug;141(2):497-511.

8. Maddox P, Sasieni P, Szarewski A, et al. Differential expression of keratins 10, 17, and 19 in normal cervical epithelium, cervical intraepithelial neoplasia, and cervical carcinoma. J Clin Pathol. 1999 Jan;52(1): 41-6.

9. Nartam Sharma, Veena Sharma, Prem Raj Singh, et al. Biomed Res-India 2012; 23(4):547-550.

10. Nazir Ahmed, Razia Mehboob. Cervical intraepithelial- neoplasia. Recent trends in diagnosis \& treatment. Pakistan J Med Research, 2002;Apr-Jun;41 (2): 43-5.

11. Torrisi A, Castagnali B, Minucci D, ACOG Committee on gynaecology practice, ACOG, Practice Bulletin no.109; cervical cytology screening, Obstetrics Gyneacol, 2009 Dec; 114(6): 1409-1420.doi10. 1097/ AOG.0b013e3181c6f8a4.

12. Herbart A, Smith JA, Department of Histopathology, Southampton General Hospital, Southampton University Hospitals NHS trust, UK Cytopathology,1999 June;10(3): 161-70.

13. Jha, A., Jha, J., Bista, R., Basnet, B., Kandel, P., Lama, G., Banthia, P., \& Thakali, K. A Scenario of Cervical Carcinoma in a Cancer Hospital. Journal of Nepal Medical Association, 2009;48(175). https://doi. org/ 10.31729/jnma.180.

14. Schiffman MH, Brinton LA. The epidemiology of cervical carcinogenesis. Cancer. 1995 Nov 15;76 (10 Suppl):1888-901.[pubmed]

15..Park TW, Fujiwara H, Wright TC. Molecular biology of cervical cancer and it's precursors.Cancer 1995 nov;76(10 suppl):1902-1913.

16. ZoeR.Edelstein, Margaret M, Madeleine, James PHughes. Cancer Epidemiol Biomarkers Prev 2009;18 (4): 1070-1076. doi: 10.1158/1055-9965.EPI-08-0707. 
17. Parveen S, Hakim S, Siddiqui S, Ahmed J. A retrospective study of female genital tract malignancies. Jour of Med Sc and Tech; 2009;Sep 12;1(3): 40-43.

18. Satya B. Paul, Basant K,Tiwari, Arun Paul Choudhary, Department of Chemistry, Assam Uni, Silichar, Assam, Assam Uni, Journal of sci and Tech, Biological and environmental science,.2011; 7(1):36-42

19. Goellner J.R.et al.Carcinoma of cervix, clinicipathological coorelation Am. J. Clinicol, Pathol,1976; 66 (5) : 775-786.

20. Verma K, Kapila K. Increase in accuracy of typing of carcinoma of the uterine cervix by combined use of histology and cytology. Acta Cytol. 1982 Mar-Apr;26 (2): 131-4.

21. Subir M, Gangare N, Bnake A, Ingote N, et al. Carcinoma of the cervix and stain for mucin. Journal of Obs and gynae of India. 1991;1(5): 678-680.

\section{Original Research Article}

22. Carla Carriho, Matos Alberto.Keratins 8, 10, 13, and 17 are useful markers in the diagnosis of human cervix carcinomas. Human pathology 2004 May; 35(5); 546-51. https//doi.org/10. 1016/j. humanpath. 2004. 01.02 .

23. Ikeda K, Tate G, Suzuki T, et al. Coordinate expression of cytokeratin 8 and cytokeratin 17 immunohistochemical staining in cervical intraepithelial neoplasia and cervical squamous cell carcinoma: an immunohistochemical analysis and review of the literature. Gynecol Oncol. 2008 Mar;108 (3): 598-602. doi: 10.1016/j.ygyno. 2007. 11.042. Epub 2008 Jan 14 .

24. Smaroula Divani, George Kalodimos; Archive of oncology, 2010 october; 18(3): 88-90.doi 10.2298/AOO $1003088 \mathrm{D}$

\section{How to cite this article?}

Bundela A, Bundela A, Vahikar S.U, Srivastava K, Goyal A.K. Comparative study of expression of keratins 8, 10, 13 and 17 in CIN III and invasive carcinoma of cervix. Trop J Path Micro 2019;5(5):309-316.doi: 10.17511/jopm.2019.i05.09. 